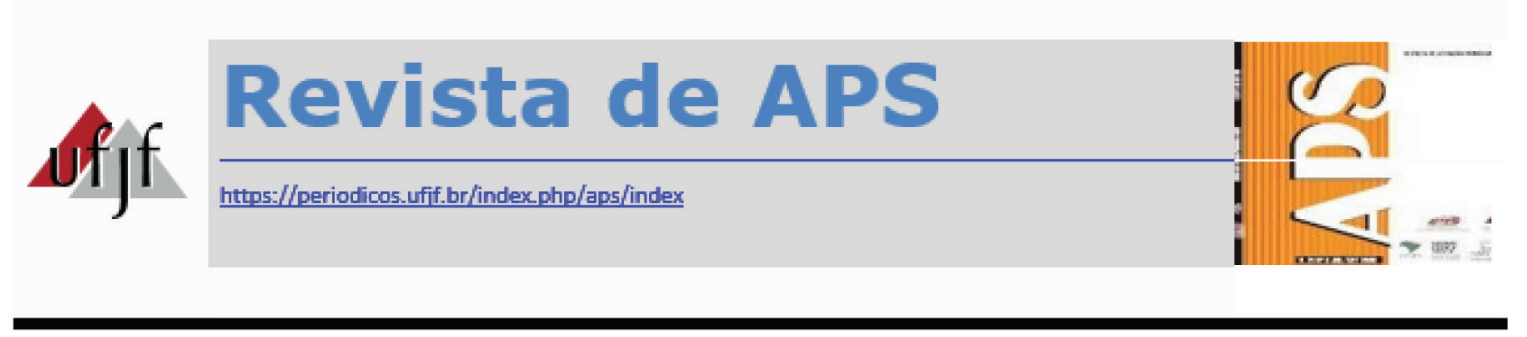

\title{
Reorientação da formação profissional em saúde: o que nos dizem os relatórios finais dos PET-SAÚDE e PRÓ-PET- SAÚDE?
}

\author{
Reorientation of vocational training in health: what do the final pet- \\ health and pro-pet-health reports tell us?
}

\author{
Quitéria Lívia Muniz Mira ${ }^{1}$, Maristela Inês Osawa Vasconcelos ${ }^{2}$, Eliany Nazaré \\ Oliveira $^{3}$, Roberta Cavalcante Muniz Lira ${ }^{4}$, Quitéria Larissa Teodoro Farias ${ }^{5}$
}

\begin{abstract}
RESUMO
Com o intuito de redirecionar o processo de formação profissional e alcançar uma assistência à saúde de qualidade que vise à substituição do modelo tradicional da organização das linhas de cuidado em saúde, o Ministério da Educação em parceria com o Ministério da Saúde desenvolveram o Programa Nacional de Reorientação da Formação Profissional em Saúde (Pró-Saúde) e o Programa de Educação pelo Trabalho para a Saúde (PET-Saúde). Esse estudo busca analisar o processo de implementação do Pró-Saúde e PET-Saúde nas universidades públicas de Sobral - CE, a partir dos relatórios finais dos referidos programas. Trata-se de uma pesquisa documental com abordagem qualitativa, onde foi utilizada a análise de conteúdo proposta por Bardin, resultando quatro categorias: repercussões para a reorientação da formação em saúde; integração ensino-serviço-comunidade; elementos facilitadores para a implementação dos programas; limitações e ações
\end{abstract}

\footnotetext{
${ }^{1}$ Enfermeira. Mestra em Saúde da Família pela Universidade Federal do Ceará (UFC). Docente de Enfermagem no Centro de Ensino Tecnológico (CENTEC)/Ensino Médio Integrado. Docente do curso de Gerência em Saúde da Universidade Estadual do Ceará (UECE)/Mediotec. E-mail: quiterialivia@hotmail.com

${ }^{2}$ Enfermeira. Doutora em Enfermagem pela Universidade Federal do Ceará (UFC). Docente do Curso de Enfermagem da Universidade Estadual Vale do Acaraú (UVA), Sobral. Membro do Laboratório de Pesquisa Social, Educação Transformadora e Saúde Coletiva.

${ }^{3}$ Enfermeira. Doutora em Enfermagem pela Universidade Federal do Ceará (UFC). Docente do Curso de Enfermagem da Universidade Estadual Vale do Acaraú (UVA), Sobral.

${ }^{4}$ Enfermeira. Doutora em Saúde Pública pela Faculdade de Saúde Pública/USP. Docente do Curso de Medicina da Universidade Federal do Ceará (UFC)/Campus Sobral.

${ }^{5}$ Graduanda em Enfermagem pela Universidade Estadual Vale do Acaraú. Membro do Laboratório de Pesquisa Social, Educação Transformadora e Saúde Coletiva (LABSUS/UVA). Bolsista de Iniciação Científica do CNPq pelo Programa Institucional de Bolsas de Iniciação Científica (PIBIC/CNPq/UVA).
} 
para superação. Acredita-se que as elucidações apresentadas no estudo contribuam para que iniciativas integradoras de ensino e serviço sejam conduzidas em suas potencialidades, permitindo a superação de entraves e viabilizando a transformação definitiva das práticas ultrapassadas, fragmentadas e reducionistas da assistência em saúde.

PALAVRAS-CHAVES: Política de Saúde. Educação Superior. Sistema Único de Saúde.

\begin{abstract}
In order to redirect the professional training process and achieve quality health care aimed at replacing the traditional model of organization of health care lines, the Ministry of Education in partnership with the Ministry of Health developed the National Health Care Program. Reorientation of Professional Health Training (Pro-Health) and Health Work Education Program (PET-Health). This study seeks to analyze the process of implementation of the Pro-Health and the PET-Health in public universities of Sobral - CE, from the final reports of these programs. This is a documentary research with a qualitative approach, using the content analysis proposed by Bardin, resulting in four categories: repercussions for the reorientation of health education; teaching-service-community integration; facilitating elements for program implementation; limitations and actions to overcome. It is believed that the elucidations presented in the study contribute to integrative teaching and service initiatives to be conducted in their full potential, allowing the overcoming of barriers and enabling the definitive transformation of outdated, fragmented and reductionist practices of health care.
\end{abstract}

KEYWORDS: Health Policy. College education. Health Unic System.

\title{
INTRODUÇÃO
}

O processo de formação dos profissionais de saúde no Brasil começou a ocupar espaço nas discussões nacionais de saúde a partir da proposta da Reforma Sanitária Brasileira, tendo em vista que para efetivar mudanças na forma de fazer saúde é necessária a reformulação do processo de formação da força de trabalho que envolve este fazer. Desde então, as iniciativas, movimentos e políticas com foco na reorientação da formação em saúde assumiram diversas configurações. ${ }^{1}$

A integralidade se tornou o eixo norteador da formação, para estar além das diretrizes e leis do sistema de saúde brasileiro. Trata-se da forma de se construir uma assistência à saúde de qualidade de forma a substituir o modelo tradicional da organização do cuidado ao ser humano. ${ }^{2}$

Entre as políticas com este propósito, é possível citar o Programa Nacional de Reorientação da Formação Profissional em Saúde (Pró-Saúde) que surgiu numa parceria do Ministério da Saúde (MS) com o da Educação (MEC), a partir da Secretaria de Gestão do Trabalho e da Educação Superior (SGTES), da Educação Superior (SESU) e com o apoio do Instituto Nacional de Estudos e Pesquisas Educacionais Anísio Teixeira (INEP). A proposta levou em conta a sustentação estrutural apontada pelas 
Diretrizes Curriculares Nacionais, estabelecidas pelo Conselho Nacional de Educação (CNE) para as profissões de saúde, bem como o Sistema Nacional de Avaliação da Educação Superior (SINAES), possibilitando intervir nos cenários de prática do serviço público, tornando-os mais próximos da realidade dos futuros profissionais e mais atraentes à sua permanência. ${ }^{3,4}$

O Programa de Educação pelo Trabalho para a Saúde (PET-Saúde) surgiu como uma proposta derivada do Pró-Saúde com o intuito de garantir o alcance dos seus objetivos, constituindo-se uma estratégia mais específica de atividades que potencializem o eixo cenário de prática do Pró-Saúde. O Programa foi instituído em 2008, no âmbito dos Ministérios da Saúde e da Educação, através da Portaria Interministerial no 1.802/08, sendo destinado a fomentar grupos de aprendizagem tutorial na Estratégia Saúde da Família (ESF). Caracteriza-se como uma das ações direcionadas ao fortalecimento da Atenção Primária à Saúde (APS), em conformidade com as necessidades do SUS e como fio condutor da interação ensino-serviço-comunidade. ${ }^{5}$

A partir do exposto, compreende-se que o Pró-Saúde e o PET-Saúde, inclusive em virtude do significativo investimento por parte dos Ministérios da Saúde e da Educação, constituem-se como estratégias potenciais para redirecionar o processo de formação profissional em saúde. Em decorrência disso, evidencia-se a necessidade de que os programas produzam resultados efetivos quanto à contribuição para a melhoria do fazer profissional no âmbito do SUS.

Diante disso, esse estudo tem como objetivo analisar o impacto da implementação do Pró-Saúde e PET-Saúde nas Universidades públicas de Sobral - CE, a partir dos relatórios finais dos referidos programas.

\section{METODOLOGIA}

Trata-se de um estudo do tipo documental, com abordagem qualitativa. A pesquisa documental "é um procedimento que se utiliza de métodos e técnicas para a apreensão, compreensão e análise de documentos dos mais variados tipos" ${ }^{\prime 6}$. O uso dessa técnica em abordagens qualitativas tem relevância, seja complementando as informações obtidas por outras técnicas, seja desvelando aspectos novos de um tema ou problema, uma vez que se volta para a descoberta, identificação, descrição aprofundada e geração de explicações. ${ }^{7,8}$

Foram analisados os relatórios finais dos seguintes programas: Pró-Saúde/PETSaúde (2012-2014) da Universidade Federal do Ceará (UFC)/Campus de Sobral e da Universidade Estadual Vale do Acaraú (UVA); PET-Saúde/Vigilância em Saúde (20132015) da UVA e PET-Saúde/Redes de Atenção (2013-2015) da UVA a partir do formulário online (FormSUS) que contempla informações relativas à identificação, desenvolvimento 
e avaliação das atividades (anuais e finais) implementadas. Excluiu-se o relatório final do PET-Saúde/Vigilância em Saúde da UFC, uma vez que havia apenas o relatório parcial de um dos grupos tutoriais, sendo este descartado por não contemplar as informações necessárias para o alcance dos propósitos do estudo.

Utilizou-se um roteiro de coleta de dados para as fontes documentais dos relatórios finais construído com enfoque nas atividades de ensino, pesquisa e extensão desenvolvidas. Foram extraídas dos documentos as informações necessárias para atender o objetivo da pesquisa.

Para a realização da análise dos relatórios técnicos, foi solicitado o acesso e anuência junto à UVA e UFC/Campus de Sobral, por meio da assinatura do Termo de Fiel Depositário pelos tutores coordenadores dos Programas. Além disso, foi emitido às referidas IES um Termo de Compromisso do Pesquisador para a utilização dos dados dos documentos garantindo a confidencialidade das informações. A anuência destes foi prérequisito para análise dos relatórios.

O material coletado foi analisado pelo método de análise de conteúdo proposta por Bardin (2011) que utiliza três fases básicas: a pré-análise, que corresponde a um período de intuições e tem por objetivo tornar operacionais e sistemáticas as ideias iniciais, direcionando o desenvolvimento das operações subsequentes, tendo em vista a análise; a exploração do material, na qual é feita a conclusão da preparação do material para a análise, em termos de operações de codificação, desconto ou enumeração, em função de regras previamente formuladas; e o tratamento dos resultados obtidos e interpretação, momento em que são feitas inferências e interpretações, conforme os objetivos previstos ou referentes a novos achados na pesquisa. Os achados foram apresentados e discutidos mediante categorias que emergiram das informações obtidas da análise de conteúdo dos documentos. ${ }^{9}$

Ressalta-se que a pesquisa foi aprovada pelo Comitê de Ética em Pesquisa (CEP) da UVA por meio do Parecer $N^{\circ}$ 1.402.426 em conformidade, portanto, com os princípios da Resolução N 466/12.

\section{RESULTADOS E DISCUSSÕES}

\section{O que nos dizem os relatórios finais dos PET-Saúde e Pró-Saúde?}

Através da análise dos relatórios finais buscou-se evidenciar aspectos correspondentes ao objetivo do estudo, consolidando-se quatro categorias temáticas relativas aos projetos PET-Saúde e Pró-Saúde: repercussões para a reorientação da formação em saúde; integração ensino-serviço-comunidade; elementos facilitadores para a implementação; limitações e ações para superação. 
Quadro 1 - Distribuição dos projetos PET-Saúde por IES e presença de evidências nos relatórios finais quanto aos aspectos: mudanças na formação; integração ensinoserviço; facilidades; limitações e ações para superação. Sobral - CE, mar. /abr. 2016

\begin{tabular}{|l|c|c|c|c|c|}
\hline \multicolumn{1}{|c|}{ PROGRAMA } & IES & \multicolumn{4}{|c|}{ CATEGORIAS } \\
\hline & $\begin{array}{c}\text { Repercussões } \\
\text { para a } \\
\text { reorientação da } \\
\text { formação }\end{array}$ & $\begin{array}{c}\text { Integração } \\
\text { ensino-serviço- } \\
\text { comunidade }\end{array}$ & $\begin{array}{c}\text { Elementos } \\
\text { facilitadores }\end{array}$ & $\begin{array}{c}\text { Limitações } \\
\text { e ações para } \\
\text { Superação }\end{array}$ \\
\hline PET-Saúde Redes & UVA & $X$ & $X$ & - & $X$ \\
Pró-Saúde/PET-Saúde & UVA & $X$ & $X$ & - & $X$ \\
Vigilância Pró-Saúde/ & UVA & $X$ & $X$ & $X$ & $X$ \\
PET-Saúde & UFC & $X$ & $X$ & - & $X$ \\
\hline
\end{tabular}

Fonte: elaborado pelas autoras

Conforme se observa no Quadro 1, os relatórios finais analisados contemplam as categorias do estudo em quase sua totalidade, com exceção da categoria "elementos facilitadores", cujos aspectos buscados não foram consolidados nos relatórios PETSaúde/Redes de Atenção UVA, Pró-Saúde/PET-Saúde UVA e Pró-Saúde/PET-Saúde UFC. As categorias serão analisadas a seguir.

\section{Repercussões para a reorientação da formação em saúde}

As mudanças na formação em saúde expressas nos relatórios analisados ocorrem de forma articulada, sendo possível identificar contribuições do Pró-Saúde e PET-Saúde em diversos aspectos da formação profissional.

É possível evidenciar que o caráter interprofissional das atividades executadas entre os diferentes cursos induziu mudanças favoráveis no sentido de redirecionar a formação em saúde dos estudantes envolvidos nos Programas. Como resultado dessa aproximação interprofissional destaca-se a incorporação das habilidades de trabalho (trabalho em equipe, interdisciplinaridade, cooperativismo, tomada de decisões, etc.), favorecendo o desenvolvimento das competências exigidas pelas DCN dos cursos envolvidos e, consequentemente, induzindo a reorientação da formação em saúde, com destaque para os conteúdos e ações desenvolvidas de forma integrada, conforme observa-se nos seguintes extratos:

Os alunos auferiram conhecimentos específicos em suas áreas, além da experiência de trabalhar e aprender em equipe juntos aos estudantes dos outros cursos, ou seja, a experiência compartilhada de conhecimentos de Medicina, Odontologia e Psicologia e o trabalho prático nos projetos, os quais todos tinham a interdisciplinaridade como principal meta, proporcionaram aos estudantes o desenvolvimento das 
competências propostas pelas novas DCNs para os cursos da saúde: trabalho em equipe, tomada de decisão, liderança, comunicação e organização do trabalho em saúde (RELATÓRIO Pró-Saúde/PET-Saúde UFC).

A formação compartilhada entre estudante de educação física e enfermagem surgiu como importante processo de mudança no Centro de Ciências da Saúde da UVA. O PET-Saúde/Redes de Atenção possibilitou a imersão destes estudantes no sistema de saúde, onde estes foram impulsionados a realizar ações integradas em vários pontos da rede de atenção. A enfermagem pode conhecer e aprimorar atividades relacionadas ao campo de conhecimento da educação física, este trabalho cooperativo trouxe crescimento acadêmico e profissional para todos os envolvidos (RELATÓRIO PET-Saúde/Redes de Atenção UVA).

As atividades interprofissionais/multiprofissionais aconteceram a partir da imersão dos monitores nos cenários de práticas. Os monitores de educação física e enfermagem compartilharam um mesmo processo de aprendizagem no decorrer das atividades, de forma a garantir a partir do diálogo, competências necessárias ao trabalho em equipe interprofissional. Todo esse processo não estava dado e foi construído com diálogo e articulações nos cursos (RELATÓRIO Pró-Saúde/PETSaúde UVA).

Entre os principais resultados do Programa para a formação dos estudantes destaca- se a valorização do trabalho em equipe e o desenvolvimento de habilidades de comunicação, contribuindo na formação de futuros profissionais enfermeiros e educadores físicos mais críticos, atuantes e compromissados (RELATÓRIO PET- Saúde/ Vigilância em Saúde UVA).

No conjunto de mudanças estimuladas pelo Pró- Saúde e PET-Saúde, a educação interprofissional vem ganhando visibilidade quando se percebe a necessidade de estimular, ainda no processo de formação, habilidades e valores que deem sustentação ao trabalho colaborativo nas equipes de saúde. ${ }^{10}$

Um outro aspecto contemplado nos relatórios, que favorece a reorientação da formação em saúde, refere-se às mudanças induzidas na matriz curricular, no projeto pedagógico e nas práticas de ensino dos cursos envolvidos. Observa-se que o PET-Saúde e o Pró-Saúde têm incitado a adoção de novas estratégias metodológicas e mudanças nos desenhos curriculares.

O relatório final do Pró-Saúde/PET-Saúde da UVA, por exemplo, aponta evidências de mudanças no ensino em saúde como resultado da articulação dos Programas, cujas atividades implementadas vem contribuindo, dentre outros aspectos, para a consolidação da nova estrutura curricular modular do curso de Enfermagem, que visa qualificar o processo de formação do enfermeiro em consonância com a rede SUS.

No primeiro semestre de 2014 concluiu a primeira turma do curso de enfermagem da UVA orientado a partir de uma nova estrutura 
curricular modular. A gestão vem desenvolvendo momentos no Curso a fim de problematizar junto aos docentes, discentes e profissionais dos serviços de saúde, que atuam como preceptores, a consolidação do sistema modular, buscando construir um plano de ação com vistas a qualificar o processo de formação do enfermeiro em consonância com a Rede SUS. O Pró-Saúde articulado ao PET-Saúde, assim como os demais PET (Vigilância, Redes de Atenção) existentes na universidade tem participado intensamente desse processo (RELATÓRIO Pró-Saúde/ PET-Saúde UVA).

Observou-se que a interação entre os diversos cursos da área da saúde propiciada pelo Pró-Saúde articulado ao PET-Saúde vem favorecendo mudanças curriculares com a adoção de novas estratégias metodológicas de ensino aprendizagem, conforme preconizam as DCN para os cursos de graduação na área da saúde. É nítido o intento de viabilizar momentos compartilhados de aprendizagem, almejando importantes ganhos para a mudança da lógica da educação profissional em saúde.

Denota-se que as mudanças curriculares advindas das atividades interprofissionais fomentadas pelos Programas são representadas, entre outros exemplos, pela implantação de disciplinas, grupos de pesquisa, projetos e cursos de extensão que buscam favorecer o exercício profissional a partir da atuação interprofissional/interdisciplinar, conforme se destaca nos trechos abaixo.

As ações de caráter interdisciplinar e interprofissionais tem impactado em mudanças curriculares nos cursos de enfermagem e educação física. Destaca-se assim, os módulos de Práticas Interdisciplinares no Ensino, Pesquisa e Extensão ( 1 ao 4) onde buscou articular experiências com outros cursos, favorecendo o exercício da atuação interprofissional/ interdisciplinar e instigando o olhar do estudante para intervir na realidade. (RELATÓRIO Pró-Saúde/PET-Saúde UVA).

Destaca-se o desenvolvimento do curso de extensão Promoção da Saúde com ênfase na Saúde do Adolescente. Trata-se de uma formação na modalidade semipresencial, com duração de 03 meses, voltado para graduandos de Enfermagem e Educação Física (prioritariamente dos últimos semestres. Além disso, ressalta-se a criação do projeto de extensão GEOSUS e do grupo de pesquisa cadastrado no CNPq/CAPES - Observatório de Pesquisas para o SUS, criado a partir da experiência de geoprocessamento pelo grupo tutorial Pró/PET-Saúde. Outra iniciativa é a criação da Liga de Saúde da Família, que intenta articular ações de extensão e pesquisa com a formação profissional (RELATÓRIO Pró-Saúde/PET-Saúde UVA).

As atividades dos projetos resultaram na qualificação das discussões dos processos de trabalho e sua implementação como política de saúde para o município, além de alguns dos projetos se consolidarem como projetos de extensão e fortalecimento das mudanças curriculares nas IES (RELATÓRIO Pró-Saúde/PET-Saúde UFC).

As DCN para área da saúde propõem a organização dos currículos integrados como uma estratégia para reduzir problemas de um currículo repleto de críticas por 
não propiciar aos alunos perceber as relações entre as diferentes disciplinas e entre prática/cotidiano profissional ${ }^{11}$. O PET-Saúde e o Pró-Saúde, ao fomentar a integração entre docentes e discentes de diferentes áreas e cursos, impulsionam o trabalho em equipe e a colaboração interprofissional, favorecendo a atuação interdisciplinar e consequentemente um ambiente propício para iniciar um processo de integração curricular.

Nos relatórios, enfatiza-se que apenas o curso de Medicina apresenta um currículo considerado integrado, enquanto o curso de Enfermagem, conforme anteriormente enfatizado, possui um currículo modular em fase de consolidação. Apoiados na perspectiva do Pró-Saúde e PET-Saúde, observa-se que os demais cursos têm desenvolvido estratégias que apontam para essa direção, denotando-se a proposição de projetos articuladores e reflexões mais profundas nessa dimensão. Tais inferências são constatadas nos trechos seguintes:

O currículo do curso de medicina passou por uma profunda reforma curricular há alguns anos, incorporando as novas Diretrizes Curriculares, na busca dos conteúdos integrados e no desenvolvimento das competências que as novas diretrizes apontam (RELATÓRIO PróSaúde/PET-Saúde UFC).

No primeiro semestre de 2014 concluiu a primeira turma do curso de enfermagem da UVA orientado a partir de uma nova estrutura curricular modular. A gestão vem desenvolvendo momentos no Curso a fim de problematizar junto aos docentes, discentes e profissionais dos serviços de saúde, que atuam como preceptores, a consolidação do sistema modular, buscando construir um plano de ação com vistas a qualificar o processo de formação do enfermeiro em consonância com a Rede SUS. O Pró-Saúde articulado ao PET-Saúde, assim como os demais PET (Vigilância, Redes de Atenção) existentes na universidade têm participado intensamente desse processo (RELATÓRIO Pró-Saúde/ PET-Saúde UVA).

Os cursos de odontologia e psicologia já estão trabalhando na modificação e atualização de seus currículos, os quais possuem um modelo ainda não centrado no aluno e com disciplinas que não são integradas, diferentemente do curso de medicina, que já possui um currículo integrado (RELATÓRIO Pró-Saúde/PET-SaúdeUFC).

Ao analisarmos os resultados da atuação do Pró-Saúde/PET-Saúde, a partir do nosso grupo de aprendizagem tutorial, percebemos que as ações de caráter interdisciplinar e interprofissionais tem impactado em mudanças curriculares nos cursos de enfermagem e educação física. Destaca-se assim, os módulos de Práticas Interdisciplinares no Ensino, Pesquisa e Extensão (I ao 4) onde buscou articular experiências com outros cursos, favorecendo o exercício da atuação interprofissional/ interdisciplinar e instigando o olhar do estudante para intervir na realidade (RELATÓRIO Pró-Saúde/PET-Saúde UVA).

Cursos da área da saúde que historicamente mantinham relação mais distanciada 
dos serviços passaram por algumas mudanças curriculares para assegurar coerência com as diretrizes do Pró-Saúde e PET-Saúde, incorporando mudanças significativas no processo de formação. ${ }^{10}$

Nesse sentido, é possível afirmar que o Pró-Saúde e o PET-Saúde vêm cumprindo seus papeis quando diversificam os cenários de aprendizagem, dando oportunidade à formação de outras habilidades e competências importantes ao profissional de saúde. ${ }^{12}$

Embora sendo nítidos os esforços envidados no sentido de promover mudanças curriculares mais densas nos cursos em questão, constatando-se inclusive alguns avanços concretos nesse âmbito, foi identificado nos relatórios, através de um questionamento sobre as repercussões favoráveis dos Programas para as IES, que a reorientação curricular dos cursos envolvidos não ocorreu efetivamente. Nos relatórios do Pró-Saúde/PETSaúde UVA e UFC consta que a reorientação curricular dos cursos envolvidos aconteceu apenas parcialmente, enquanto no PET-Saúde/Redes de Atenção UVA, essas mudanças não ocorreram.

Convém destacar que no relatório final do PET-Saúde/Vigilância em Saúde da UVA não constam informações relativas às mudanças curriculares e às práticas de ensino induzidas pelo Programa. No entanto, denota-se de forma sucinta e implícita que o PET-VS viabilizou o trabalho em equipe e oportunizou aos alunos o aprofundamento da epidemiologia como temática relevante para a saúde pública, ainda pouco abordada nas matrizes curriculares dos cursos (Enfermagem e Educação Física). O documento, em contrapartida, não pontua aspectos mais contundentes relativos à subcategoria pertinente.

\section{Contribuições para o fortalecimento da integração ensino-serviço-comunidade}

A integração ensino-serviço-comunidade pode ser conceituada como o trabalho coletivo, pactuado e integrado de estudantes e professores das IES com os trabalhadores dos serviços de saúde, incluindo-se os gestores, e a comunidade, objetivando qualificar a atenção à saúde individual e coletiva e à qualidade da formação profissional ${ }^{13}$. Dessa forma, a interação entre as IES, os serviços de saúde do SUS e as comunidades é reconhecida como veículo para se alcançar a adequação dos profissionais às demandas sociais da população. ${ }^{14}$

Desenvolvido para tal propósito, o Pró-Saúde propõe a articulação intersetorial como o principal objetivo do Programa. O documento oficial mostra que o objetivo geral do programa é a integração ensino-serviço-comunidade, visando à reorientação da formação profissional, assegurando uma abordagem integral do processo saúdedoença com ênfase na atenção básica, promovendo transformações nos processos de geração de conhecimentos, ensino e aprendizagem e de prestação de serviços à população. ${ }^{4}$ 
Seguindo essa premissa, o PET-Saúde enquanto estratégia do Pró-Saúde caracteriza-se como uma das ações direcionadas ao fortalecimento da APS, em conformidade com as necessidades do SUS e como fio condutor da integração ensinoserviço-comunidade, eixo básico para reorientar a educação na área da saúde. ${ }^{5}$

Nessa perspectiva, foi possível identificar, em todos os relatórios finais, evidências do fortalecimento da integração ensino-serviço-comunidade como consequência das atividades desenvolvidas pelos grupos tutoriais durante os Programas. Os trechos abaixo confluem para certificar essa inferência.

As ações desenvolvidas incentivam e fortalecem a integração ensino/ serviço/comunidade para uma formação profissional contextualizada com o SUS. Os resultados são incorporados pela universidade e serviços de saúde para reflexão, avaliação e produção de conhecimento (PróSaúde/PET-Saúde UVA).

As intensas atividades relacionadas aos projetos possibilitaram a integração ensino- serviço. Estreitamente ligados, estes dois campos de atuação foram o palco para o desenvolvimento de atividades de ensino, pesquisa e extensão, gerando projetos de extensão cujas ações se incorporaram aos currículos dos três cursos e que mantém uma continuidade para além dos PRÓ/PET-Saúde (Pró-Saúde/PETSaúdeUFC).

A articulação existente entre a IES e a gestão municipal sempre se deu de forma contínua na formação de profissionais do SUS. Com as atividades do PET/VS, o elo existente foi fortalecido a cada dia, por meio da comunicação efetiva, trabalho e vivências entre monitores, preceptores e tutor. Entre os principais resultados do grupo tutorial para a formação dos estudantes está, efetivamente, a contribuição para aproximar as teorias e os conceitos com a prática profissional (PET-Saúde/Vigilância em Saúde UVA).

Entre as repercussões favoráveis do projeto para o serviço, a comunidade, a IES e os participantes, citam-se a articulação entre a IES e a gestão municipal, a aproximação da IES com a prática da Atenção Primária em Saúde (APS), aproximação da IES com a prática das Redes de Atenção à Saúde e o desenvolvimento das atividades com foco nas necessidades da comunidade/serviços de saúde (PET-Saúde/Redes de Atenção UVA).

O processo de articulação do ensino e serviço, incentivado pelo Pró-Saúde e PETSaúde, pode ser identificado como a principal característica e ganho dessa estratégia política. Não apenas pela adoção de novos cenários de prática, ou de novas estratégias mais ativas e dinâmicas de ensino e aprendizagem, mas pela capacidade de estimular o pensamento crítico, a reflexão e a responsabilidade social diante dos problemas e experiências vivenciadas. ${ }^{15}$

Como atividades que impulsionam o fortalecimento da integração ensinoserviço-comunidade, apontam-se nos relatórios analisados as ações de ensino, pesquisa 
e extensão desenvolvidas a partir das experiências vivenciadas pelos alunos nos diversos cenários deformação e estratégias de aprendizagem propiciadas pelos Programas. A ênfase no desenvolvimento de pesquisas e ações de extensão podem ser identificadas nos extratos seguintes:

Estreitamente ligados estes dois campos (ensino-serviço) foram o palco para o desenvolvimento de atividades de ensino, pesquisa e extensão, gerando projetos de extensão cujas ações se incorporaram aos currículos dos três cursos e que mantém uma continuidade para além dos PRÓ/PET-Saúde (Pró-Saúde/PET-Saúde UFC).

Integração ensino, extensão e pesquisa aconteceu concomitantemente e foram importantes para o processo de formação na saúde [...] as pesquisas foram desenvolvidas a partir das práticas vivenciadas nos serviços que integram as redes, mas com projetos específicos aprovados pelo comitê de ética, possibilitando o exercício dos participantes em diferentes métodos de construção de conhecimento (PET-Saúde/ Redes de Atenção UVA).

Os estudantes participaram das atividades de pesquisa e de assistência em todas as fases de seu desenvolvimento, desde o planejamento, execução e avaliação (Pró-Saúde/PET- Saúde UVA).

De modo orgânico e sistêmico ocorreram as ações de investigação e intervenção das pesquisas do PRÓ-Saúde/PET-Saúde possibilitando o trabalho interprofissional, desde a gênese do projeto de pesquisa até a coleta de dados, intervenção e análise dos resultados (Pró-Saúde/ PET-Saúde UVA).

Entre as principais ações desenvolvidas para o alcance dos objetivos propostos estão a produção científica e desenvolvimento de projetos de pesquisa (PET-Saúde/Vigilância em Saúde UVA).

A pesquisa se configura como um potente instrumento para as mudanças na formação em saúde. A produção do conhecimento se aproxima da realidade dos serviços e da vida das pessoas, elaborando produções que são capazes de iluminar mudanças na realidade destes serviços de saúde. Além disso, a pesquisa estimulada no âmbito do PET-Saúde aproxima os profissionais de saúde dos alunos, retomando um ritmo de qualificação importante para a melhoria da qualidade da atenção à saúde. ${ }^{16,17}$

Na perspectiva das ações de extensão na comunidade, verifica-se nos relatórios que estas representam um quantitativo expressivo das atividades desenvolvidas durante os Programas e constituem-se em momentos oportunos de construção de conhecimentos, trabalho em equipe, aproximação da realidade, desenvolvimento da sensibilidade e de vivências de novas formas de cuidado. Os trechos seguintes exemplificam o inferido:

As atividades de Extensão compreenderam as ações de práticas dos estudantes nos serviços, desenvolvidas em conjunto com os preceptores que atuam nas redes de cuidados propostas, considerando uma carga horária de, no mínimo, 8 horas semanais (PET-Saúde Redes de Atenção UVA). 
Entre as principais ações desenvolvidas destacam-se o acompanhamento de atividades de mutirão de limpeza e mobilização social para o combate à dengue; execução de atividades de educação em saúde para controle da dengue para públicos diversos como escolares, seus pais e operários em seu local de trabalho, etc. (PETSaúde Vigilância em Saúde UVA).

A vivência dos estudantes na comunidade é uma oportunidade de transferir para a prática o conhecimento adquirido na sua formação, propiciando uma ampliação da visão dos estudantes acerca do processo saúde-doença ${ }^{18}$. As ações extensionistas na comunidade podem resultar em sentimento de utilidade, oportunidade de aprendizagem pessoal e profissional. Assim, é de suma importância a atuação de estudante e docentes na comunidade, pois esta, além de ser de grande relevância acadêmica, possibilita a reflexão acerca da indissociabilidade do ensino-pesquisa-extensão e a vivência do trabalho interdisciplinar. ${ }^{19}$

Ainda no sentido do fortalecimento da integração entre ensino e serviço, outro aspecto destacado nos relatórios foi a importância dos preceptores e tutores dos Programas no apoio efetivo para essa articulação e direcionamento das pesquisas desenvolvidas, conforme pode-se observar nos trechos seguintes.

O papel dos tutores foi caracterizado pelas intensas atividades relacionadas aos projetos que possibilitaram a integração ensinoserviço (RELATÓRIO Pró-Saúde/PET-Saúde UFC).

Os tutores são responsáveis pela integração ensino - serviço. Foram responsáveis pela condução das pesquisas e ajudaram - coordenador a pensar estratégias de aprimoramento para melhor e efetiva inserção dos monitores nos serviços e articulação com os outros programas já citados. Foram responsáveis pelo monitoramento das atividadesdeensinoepesquisa. Apoiaramacoordenaçãonasaçõesintegradascoletivas (RELATÓRIO PETSaúde/Redes de AtençãoUVA).

O papel dos preceptores foi indispensável para a inserção-atuaçãoaprendizagem dos monitores nas ações/atividades nos territórios. A participação ativa e presente dos preceptores nos PET-Saúde em Sobral consolidou a compreensão do que estamos chamando de sistema saúdeescola. Graças ao PET-Saúde, o sistema de saúde de Sobral pode dizer que vivencia um sistema de saúde-escola, um sistema de saúde aprendente, que articula alunos do ensino técnico profissional, da graduação, da residência e dos mestrados com profissionais do serviço numa rede de colaboração interprofissional atuante e produtiva. O PET-Saúde veio consagrar esse vínculo entre serviço-ensino- comunidade e os preceptores compreendem seu papel como corresponsáveis pela formação profissional em saúde (RELATÓRIO Pró-Saúde/PET-Saúde UVA).

Observa-se, portanto, a importância estratégica do tutor e preceptor para transformações no processo de trabalho da equipe, bem como o seu papel no impulsionamento da articulação ensino-serviço-comunidade, que é visível nos relatórios. 
O sucesso do PET-Saúde, indubitavelmente, mantém relação direta com o grau de compromisso e empenho dos seus protagonistas, o que quer dizer que ele pode se configurar de maneira mais efetiva ou não a depender da postura adotada pelos sujeitos integrantes. ${ }^{20}$

Ainda considerando o intento do Pró-Saúde e PET-Saúde em viabilizar a integração ensino-serviço-comunidade, verificaram-se nos relatórios estratégias de sustentabilidade deflagradas pelos programas, objetivando a continuidade das atividades implementadas mesmo após a finalização dos projetos. Os seguintes extratos referentes ao Pró-Saúde/ PET-Saúde da UVA e UFC exemplificam o enunciado.

Dentre as estratégias de sustentabilidade dos resultados do programa, destaca-se a representação de docentes do Centro de Ciências da Saúde na CIES da macrorregião de saúde Sobral, bem como nos processos de educação permanente em saúde que estão sob a tutela da Escola de Formação em Saúde da Família Visconde de Sabóia. Ressaltase ainda a criação de grupos de pesquisa e projetos de extensão interdisciplinares, como também a aproximação dos preceptores com a IES a partir da realização de oficinas, internatos, momentos em sala de aula e acompanhamento e acolhida dos estudantes nos cenários de prática (Pró-Saúde/PET-Saúde UVA).

Ressalta-se a criação do projeto de extensão GEOSUS e do grupo de pesquisa cadastrado no CNPq/CAPES - Observatório de Pesquisas para o SUS, criado a partir da experiência de geoprocessamento pelo grupo tutorial PRÓ/PET-Saúde (Pró- Saúde/PET-Saúde UVA).

O ensino e o serviço foram o palco para o desenvolvimento de atividades de ensino, pesquisa e extensão, gerando projetos de extensão cujas ações se incorporaram aos currículos dos três cursos e que mantém uma continuidade para além dos PRÓ/PET- Saúde (PróSaúde/PET-Saúde UFC).

Alguns projetos, além de incorporados como extensão na Universidade, e sendo a comunidade o alvo das ações, eles permanecem em funcionamento, a despeito do término do PET-Saúde, como o Projeto Coala, que foi iniciado no PET-Saúde e agora faz parte da política de saúde da criança da secretaria de saúde de Sobral. Este projeto proporciona um atendimento intensivo à criança prematura após sua saída do período de internação hospitalar (Pró-Saúde/PET-Saúde UFC).

As atividades dos projetos resultaram na qualificação das discussões dos processos de trabalho e sua implementação como política de saúde para o município, além de alguns dos projetos se consolidarem com os projetos de extensão e fortalecimento das mudanças curriculares nas IES (Pró-Saúde/PET-Saúde UFC).

Conforme o exposto, notam-se resultados profícuos e consistentes dos Programas na consolidação da integração ensino-serviço-comunidade para além de estratégias pontuais, demonstrando o potencial do PET-Saúde e Pró-Saúde em provocar mudanças efetivas na reorientação da formação profissional em saúde. 
Cabem, assim, reflexões sobre aspectos que possam estar relacionados à complexidade em efetivar as atividades desenvolvidas pelo Pró-Saúde e PET-Saúde para além do desfecho dos Programas. Como asseverar a viabilidade de permanência dos projetos - o engajamento dos alunos, preceptores e tutores nas atividades - sem o devido incentivo financeiro representado pelas bolsas? Seria o incentivo financeiro imprescindível para a participação dos atores?

\section{Elementos facilitadores para a implementação dos programas}

Os aspectos facilitadores e os obstáculos que operam ao longo do processo de implementação de um Programa condicionam, positiva ou negativamente, o cumprimento das metas e objetivos propostos. A dimensão temporal e as estratégias que orientam sua implementação podem ser aferidas e vinculam-se, geralmente, a diferentes processos, por exemplo, aos atores mobilizados nos diferentes estágios para sustentarem seu desenvolvimento, aos mecanismos de comunicação, à suficiência de recursos financeiros, aos critérios de seleção dos participantes e qualificação dos implementadores e beneficiários. ${ }^{21}$

Ao proceder à análise documental, foi possível constatar que apenas os relatórios finais inerentes aos dois grupos tutoriais do PET-Saúde/Vigilância em Saúde da UVA - Grupo análise de situação de saúde e fatores biológicos de risco e Grupo vigilância epidemiológica da sífilis e violências - pontuam aspectos considerados como facilitadores para o processo de implementação do programa. Nos demais relatórios não há perguntas que contemplem tais elementos, o que justifica a ausência de informações sobre o aspecto em discussão.

Nos relatórios do PET-Saúde/Vigilância em Saúde UVA foram enumerados elementos que contribuíram para o alcance dos objetivos propostos pelo programa, que podem ser constatados nos trechos que seguem.

Um dos aspectos que mais facilitou o desenvolvimento das ações programáticas foi a facilidade de inserção no serviço de saúde por meio da preceptoria. A abertura do serviço e boa receptividade dos profissionais foi algo marcante durante o aprendizado sobre vigilância em saúde. Além disso, podemos citar também o acesso facilitado pelos preceptores aos bancos de dados dos sistemas de informação em saúde, a integração da equipe de monitores com preceptores e tutor, a corresponsabilização no desenvolvimento das ações, a escuta, a acolhida de ideias e novos projetos por meio de monitores, preceptores e tutores e o encorajamento constante para o desenvolvimento de trabalho bem feito (PET-Saúde/Vigilância em Saúde - UVA. Grupo vigilância epidemiológica da sífilis e violências).

Entre os aspectos facilitadores para o alcance dos objetivos deste grupo tutorial citam- se a motivação dos monitores para realização das atividades; facilidade de integração entre as Instituições (Universidade/ 
Prefeitura Municipal de Sobral); atuação conjunta dos preceptores e monitores; boa receptividade nas atividades que envolveram a comunidade; acesso a meios e materiais que possibilitaram o desenvolvimento dos trabalhos (PET-Saúde/Vigilância em Saúde-UVA. Grupo análise de situação de saúde e fatores biológicos de risco).

Um estudo avaliativo desenvolvido durante o PET-Saúde/Vigilância em Saúde da Universidade Federal de Santa Maria (UFSM) teve como objetivo identificar as dificuldades e facilidades vivenciadas, e as contribuições do programa para o ensino e/ou para o serviço. Entre as principais facilidades referidas, destacaram o uso de ferramentas de facilitação (facilidade de comunicação interpessoal, criatividade, flexibilidade de horários, disponibilidade de material no $\operatorname{Dropbox}^{\circledR}, \operatorname{cursos}$ de metodologia científica) e a integração multiprofissional (integração entre alunos, preceptores, tutores; ajuda dos coordenadores e preceptores; divisão em pequenas equipes e comissões; boa convivência com os colegas; satisfação em trabalhar com pessoas). ${ }^{22}$

Indubitavelmente o sucesso do programa mantém relação direta com o grau de compromisso e empenho dos seus protagonistas, o que quer dizer que ele pode se configurar de maneira mais efetiva ou não a depender da postura adotada pelos sujeitos integrantes, principalmente os estudantes. ${ }^{20}$

\section{Limitações e ações para superação}

Alguns aspectos foram pontuados como fragilidades ocorridas ao longo da implementação dos projetos, implicando em limitações para o alcance dos objetivos propostos. A dificuldade de articulação de horários entre os integrantes dos grupos tutoriais, bem como a complexidade de conciliação da grade curricular dos estudantes para o desenvolvimento das atividades interdisciplinares em campo, foram fragilidades em comum apontadas pelos programas, exceto o Pró-Saúde/PET-Saúde UFC.

Diante de tais percalços, algumas estratégias de superação foram implementadas no intento de conciliar os horários livres na grade curricular dos alunos ao desenvolvimento das atividades propostas junto aos demais membros dos grupos tutoriais. Como estratégia resolutiva para esse impasse, o PET-Saúde/Redes de atenção UVA, por exemplo, optou pelos sábados para o desenvolvimento das ações integradas na comunidade, dia em que todos os alunos apresentavam disponibilidade para engajamento nas atividades. Já um dos grupos do PET-Saúde/Vigilância em Saúde UVA procedeu à construção de uma agenda mínima de encontros periódicos com momentos de vivencias grupais, sendo estabelecidos prazos adequados e monitoramento para o cumprimento das atividades.

De forma convergente, investigações em torno dos PET-Saúde desenvolvidas nas regiões Sul e Sudeste apontaram a indisponibilidade e a incompatibilidade entre os horários dos participantes como uma relevante dificuldade para o alcance da efetiva operacionalização do Programa. ${ }^{23-27}$ 
Outro aspecto destacado de forma enfática nos relatórios como fator limitante para o alcance dos objetivos pré-estabelecidos pelo Pró-Saúde/PET-Saúde UFC e UVA, diz respeito ao atraso no repasse dos recursos financeiros pelo Ministério da Saúde, cuja liberação ocorreu somente ao final do segundo ano do Programa, fator este que comprometeu a execução dos planos de trabalho, não implicando, contudo, na descontinuidade das atividades dos PET-Saúde. Ademais, destaca-se a burocratização das instâncias superiores no repasse das verbas às IES. Essas limitações são constatadas nos trechos que seguem:

As dificuldades não superadas ou ainda em vias de superações são principalmente em relação ao uso dos recursos, que esbarrou na demora no repasse, chegando os recursos ao final do segundo ano dos projetos e também a burocracia que envolve o uso deste dinheiro, especialmente da IES (Pró-Saúde/PET-Saúde UFC).

A execução do plano de trabalho referente ao recurso do Pró-Saúde para Universidade Estadual Vale do Acaraú foi comprometida, uma vez que parte do recurso chegou somente no final do ano de 2014. Além disso, alguns empasses referentes a legislação estadual fizeram com que fosse necessário solicitar ajustes no Plano de trabalho (PróSaúde/PET-Saúde UVA).

As atividades previstas em cada um dos três eixos do Pró-Saúde que dependiam de recursos financeiros para sua execução não avançaram, uma vez que parte do recurso só chegou somente no final do ano de 2014 (Pró-Saúde/PET-Saúde UVA).

Um estudo avaliativo que buscou identificar potências e fragilidades do Pró/ PET-Saúde expressas em relatórios de visitas avaliativas realizadas por assessores do MS mostra que muitos gestores apontam que os reconhecidos e esperados avanços decorrentes dos programas têm sido penalizados pelos trâmites administrativos ligados ao MS e que afetam o custeio. Essa inferência exigiu, através da postura mediadora dos avaliadores, que fossem reportados ao MS os lapsos na condução do processo e a necessidade de rever e destravar os pontos de estrangulamento, sob pena de se prejudicar o alcance dos objetivos do Pró/PET. ${ }^{28}$

Além dos aspectos supracitados, outros elementos dos relatórios analisados foram pontuados como limitadores para o alcance dos objetivos estabelecidos pelos programas. O Pró-Saúde/PET-Saúde UFC apontou a rotatividade de estudantes e preceptores como uma fragilidade ocorrida parcialmente durante a implementação do programa, devido, respectivamente, à conclusão de curso da maioria dos estudantes participantes do projeto, sendo essa fragilidade superada mediante a convocação dos aprovados na seleção que não foram contemplados na primeira chamada, e à vontade própria dos tutores, justificandose, principalmente, pela mudança de cidade e convocação em outros processos seletivos. A superação desta fragilidade foi prontamente contornada devido ao grande interesse dos demais profissionais dos serviços de saúde em participar do projeto. 
O Pró-Saúde/PET-Saúde UVA, além das fragilidades já discutidas, enumera outros aspectos considerados entraves para a efetiva operacionalização do programa. As poucas experiências de integração entre o Pró-Saúde e os PET-Saúde (PET-Saúde/ Redes de Atenção e PET-Saúde/Vigilância em Saúde) e a dificuldade de aproximação dos representantes do controle social nas atividades do grupo tutorial foram outras fragilidades apontadas pelo programa.

Como ações desenvolvidas para superação das fragilidades apontadas no relatório final do Pró-Saúde/PET-Saúde UVA, foram realizados momentos de avaliação, de forma a possibilitar o reconhecimento das fragilidades e estabelecer propostas de superação. Tais encontros consistiam em momentos de escuta e reconhecimento dos fatores restritivos e facilitadores do grupo tutorial, sendo construídos, posteriormente, planos estratégicos de superação das dificuldades.

O PET-Saúde/Vigilância em saúde - Grupo análise de situação de saúde e os fatores biológicos de risco - destacou o curto tempo para encontros de integração e socialização das atividades; atraso no cumprimento das tarefas; dificuldades dos monitores em determinados temas e alterações de situações que exigiram novas proposições. Com o propósito de enfrentamento das dificuldades apresentadas, algumas ações foram implementadas: o estabelecimento de prazos adequados e monitoramento do cumprimento das atividades; subsídio de referências bibliográficas, participação em alinhamentos teóricos e capacitação dos monitores em algumas áreas como na utilização de programas para análise de saúde; adequação dos objetivos propostos a situações que não estavam previstas como o aumento dos casos de dengue em julho de 2014.

Ainda em relação ao PET-Saúde/Vigilância em saúde UVA, o grupo tutorial Vigilância Epidemiológica da Sífilis e das Violências enfatizou a dificuldade encontrada em buscar formas diferentes de abordar e trabalhar a violência e acidentes, tendo em vista a subjetividade dessa temática e a abrangência do assunto. Como estratégia de superação para a fragilidade apresentada, foram realizadas ações intersetoriais, uma vez que foi denotada a impossibilidade de trabalhar a temática das causas externas de forma isolada. Nesse sentido, foram desenvolvidos seminários e fóruns municipais, abertos ao público, além de reuniões e planejamento de ações com gestores e profissionais da saúde que visaram a discussão e o fomento de políticas públicas municipais no combate aos agravos.

\section{CONSIDERAÇÕES FINAIS}

Os resultados do estudo evidenciaram o PET-Saúde e o Pró-Saúde como poderosos instrumentos de indução de mudanças na formação profissional em saúde nas Universidades públicas de Sobral - CE. As ações de caráter interprofissional e interdisciplinar desenvolvidas no âmbito do ensino, pesquisa e extensão, aliadas 
às facilidades de implementação e potencialidades dos programas, favoreceram o fortalecimento da integração ensino-serviço- comunidade no contexto local.

Observa-se, todavia, a necessidade de pensar a formação profissional em saúde para além dos limites dos programas de ensino em serviço, estes são indutores de novos modelos de formação em saúde, mas não devem constituir-se como estratégias únicas, ou representar a única opção viável para propostas de investimentos direcionadas a preparação dos profissionais da saúde.

É relevante que mudanças efetivas passem a ocorrer nos currículos e que propostas de currículo integrado possam ser implementadas nos diversos cursos da área da saúde. Estratégias de sustentabilidade dos resultados alcançados pelo Pró-Saúde e PET-Saúde também são imprescindíveis para que novos vieses sejam vislumbrados no sentido de propiciar a efetiva articulação entre o ensino, o serviço e a comunidade.

As recomendações sugeridas, bem como os resultados e discussões elencados nesse estudo, constituem-se como poderosos subsídios de aprimoramento para futuras edições do PET-Saúde. Espera-se que as elucidações apresentadas contribuam para que iniciativas integradoras de ensino e serviço sejam conduzidas em suas potencialidades, permitindo a superação de entraves e viabilizando a transformação definitiva das práticas ultrapassadas, fragmentadas, isoladas e reducionistas.

\section{REFERÊNCIAS}

1. Dias HSA, Lima LD, Teixeira M. A trajetória da política nacional de reorientação da formação profissional em saúde no SUS. Ciênc Saúde Coletiva. 2013; 8(6):1613-24.

2. Gonze GG, Silva GA. A integralidade na formação dos profissionais de saúde: tecendo valores. Rio de Janeiro. Physis. 2011; 21(1).

3. Ministério da Saúde. Ministério da Educação (Brasil). Pró-Saúde: Programa Nacional de Reorientação da Formação Profissional em Saúde. Brasília, DF: Ministério da Saúde, Ministério da Educação, 2005.

4. Ministério da Saúde. Ministério da Educação (Brasil). Programa Nacional de Reorientação da Formação Profissional em Saúde - PRÓ-Saúde: objetivos, implementação e desenvolvimento potencial. Brasília, DF: Ministério da Saúde; Ministério da Educação, 2007.

5. Ministério da Saúde. Ministério da Educação (Brasil). Portaria Interministerial no 1.802, de 26 de agosto de 2008. Instituído o Programa de Educação pelo Trabalho para a Saúde- PET-Saúde. Diário Oficial da União, 2008 [Internet]. [acesso em 2018 mar 25]. Disponível em: http://portal.saude.gov.br/portal/arquivos/pdf/ portariainterm1802260808.pdf.

6. Sá-Silva JR, Almeida CD, Guindani JF. Pesquisa documental: pistas teóricas e metodológicas. Revista Brasileira de História \& Ciências Sociais. 2009; 1. 
7. Duarte R. Pesquisa qualitativa: reflexões sobre o trabalho de campo. CadPesquiv. 2002; 115:139-54.

8. Minayo R, Maria CS. O desafio do conhecimento: pesquisa qualitativa em saúde. 12a ed. São Paulo: Hucitec Editora; 2010. 407 p.

9. Bardin L. Análise de Conteúdo. Análise de Conteúdo: edição revista e ampliada. São Paulo: Edições 70; 2011.

10. Costa MV, Borges FA. O Pró-PET Saúde frente aos desafios do processo de formação profissional em saúde. Interface (Botucatu). 2015; 19(Supl. 1):753-63.

11. Danielski K, Meneghel SM. Formação em saúde:elementos para debater o currículo integrado em enfermagem. In: ANDRADE MRS, et al., organizadora. Formação em Saúde: Experiências e pesquisas nos cenários de prática, orientação teórica e pedagógica. 1a ed. Blumenau: Edifurb; 2011. p. 201-14.

12. Silva MAM, et al. O Pró-Saúde e o incentivo à inclusão de espaços diferenciados de aprendizagem nos cursos de odontologia no Brasil. Interface (Botucatu). 2012; 16(42):707-17.

13. Albuquerque GSC, et al. Educação pelo trabalho para a formação do médico. Trabalho, Educação e Saúde, Rio de Janeiro. 2013 maio-ago; 11(2): 411-30.

14. Araújo ME. Palavras e silêncios na educação superior em odontologia. Ciência \& Saúde Coletiva. 2006; 11(1):179-82.

15. Boelen C, Woollard B. Social accountability and accreditation: a new frontier for educational institutions. Med Educ. 2009; 43(9):887-94.

16. Haddad AE, et al. Programa de Educação pelo Trabalho para a Saúde -PET-Saúde. Cad ABEM. 2009; 5:6-12.

17. Abrahão AL, et al. A pesquisa como dispositivo para o exercício no PET-Saúde UFF/ FMS Niterói. Rev Bras Educ Med. 2011; 35(3):435-40.

18. Souza MHN, et al. Experiências de ensino-aprendizagem deestudantes de enfermagem em uma comunidade do município do Rio de Janeiro. Esc. Anna Nery Rev. Enferm. v. 10, n. 2, p2517.ago. 2006.

19. Freitas PH, et al. Repercussões do PET-Saúde na formação de estudantes da área da saúde. Escola Anna Nery (impr.) [Internet]. 2013 jul-set [acesso em 2018 mar 25]; 17(3):496-504. Disponível em: http://www.scielo.br/scielo.php?script=sci_ arttext\&pid=S1414-81452013000300496.

20. Fonseca GS. Programa de Educação pelo Trabalho para a Saúde da Universidade de São Paulo (Campus Capital): estudo avaliativo. [Dissertação] Mestrado em Ciências Odontológicas. Universidade de São Paulo- USP/ Campus Capital. 2012.

21. Draibe SM. Avaliação de Implementação: esboço de uma metodologia de trabalho em políticas públicas. In: Barreira MCRN; Carvalho MCB, organizadoras. Tendências 
e Perspectivas na Avaliação de Políticas e Programas Sociais. São Paulo: IEE/PUC-SP; 2006.

22. Flores LM, et al. Avaliação do Programa de Educação pelo Trabalho para Saúde - PET-Saúde/Vigilância em Saúde pelos seus atores. Interface (Botucatu). 2015; 19(Supl. 9):23-30.

23. Caldas JB, et al. A percepção de alunos quanto ao Programa de Educação Pelo Trabalho para a Saúde - PET-Saúde. RevBrasEduc Med [Internet]. 2012 [acesso em 2018 mar 25]; 36(1 Supl. 2):33-41. Disponível em: http://www.scielo.br/scielo. php?pid=S0100-55022012000300006\&script=sci_arttext.

24. Albuquerque VS, et al. Integração ensino-serviço no contexto dos processos de mudança na formação superior dos profissionais da saúde. Rev BrasEduc Méd. 2008; 32(3):356-62.

25. Santos KT, et al. Percepção discente sobre a influência de estágio extramuro na formação acadêmica odontológica. Rev. OdontoUNESP [Internet].2013 nov-dez [acesso em 2018 mar. 25]; 42(6):420-25. Disponível em: http://www.scielo.br/scielo. php?pid=S1807-25772013000600005\&script=sci_arttext.

26. Pinto ACM, et al. Percepção dos alunos de uma universidade pública sobre o Programa de Educação pelo Trabalho para a Saúde. Ciência \& Saúde Coletiva [Internet]. 2013 [acesso em 2018 mar. 25]; 18(8):2201-10. Disponível em: http:// www.scielosp.org/scielo.php?script=sci_arttext\&pid=S1413-81232013001600004.

27. Fonseca GS, Junqueira SR. Programa de Educação pelo Trabalho para a Saúde da Universidade de São Paulo (Campus Capital): o olhar dos tutores. Ciência \& Saúde Coletiva [Internet]. 2014 [acesso em 2018 mar. 25]; 19(4):1151-62. Disponível em: http://www.scielo.br/scielo.php?pid=S1413-81232014000401151\&script=sci_ arttext.

28. Sordia MRL, et al.O potencial da avaliação formativa nos processos de mudança da formação dos profissionais da saúde. Interface (Botucatu). 2015; 19 Supl. 1:731-42.

Submissão: agosto de 2018.

Aprovação: novembro de 2019. 